\title{
Fire in the earth sciences
}

\author{
Research School of Earth Sciences, Australian National University, Canberta, A.C.T. 0200, Australia
}

\begin{abstract}
The earth sciences has a major role to play in elucidating the links between fire, humanity and the global environment. Currently, this emerging area of research is hampered by a lack of agreed definitions for the carbonaceous products of biomass burning, and a lack of agreed analytical protocols which make it impossible to directly compare the results of individual studies. With an appropriate suite of chemical and instrumental techniques in place, it will be possible to start untangling the complicated linkagess between fire, climate, vegetation and humans.
\end{abstract}

As long as there has been reduced carbon. sufficient oxygen and a source of ignition, there has been fire. For many years carth scicntists have reported evidence of lire in the geologic record. from the earliest occurrence of fusain in sediments of Devonian age to geochemical evidence of "global wildfires" following a meteorite impat at the K/T boundary (Wolbach et al.. 1988), to records of fire incidence inferred from charcoal abundance in marine and lacustrine sediments (Herring, 1986: Kershaw, 1986). The importance of tire in the modern world has been graphically demonstrated in recent months by the catastrophic fires which swept through the forests of Indonesia and Malaysia in the wake of an El Niño induced drought.

In the last decade, fire has received closer attention from many sections of the scientific community, including the earth sciences, following recognition of the role that anthropogenic biomass burning' plays in increasing the levels of greenhouse gases such as $\mathrm{CO}_{2}$ in the atmosphere. Currently, one third of anthropogenic $\mathrm{CO}_{2}$ emissions to the atmosphere are thought to derive from biomass burning sources, mostly from burning of lorests and savannas in tropical regions. There is a certain irony in the observation that the tool which has underpinned the rise of Homo sapiens from stone-age to space-age, now also underlies a major threat to the global climate system from both fossil fuel combustion and anthropogenic biomass burning.

The link between humanities' ancestors and fire goes back at least 1.4 million years, as evidenced by the presence of stone tools. smashed animal bones and clay baked to several hundred degrees at Chesowanja in East Africa (Gowlet et at., 1981). While such evidence does not prove that homonids had the capacity to make fire at that time, a new find of intact hearths in Brittany does suggest that fire was actively being used by Homo erectus by at least 400,000 years ago (Monnier, et al., 1994). Determining the antiquity of humanities use of fire is important for two reasons: (i) there are implications for human social evolution because, as quoted by Balter (1995) "If they're (H. erectus) just burning meat to stuff in their mouths, they're a different kind of animal than if they're sitting around a fire talking while they do it", and (ii) through the acquisition of fire as a tool, humans gained a potent agent for environmental change.

The latter of these two is of relevance to the earth sciences, as it is only though an understanding of how fire regimes have evolved in response to "natural' climatic forcing prior to any possibility of human influence, that we can hope to understand the degree to which the imposition of anthropogenic fire regimes in the more recent past may have led to modifications of 'natural' ecosystems. Such information is of particular importance in view of the fact that there is a sound theoretical base for expecting fire-related changes in vegetation patterns to affect at least regional climate/paleoclimate (Shukla et al., 199(); Xue, 1993). This is because the type of vegetation cover is an important determinant of parameters such as albedo, moisture balance, rainfall, temperature and the length of the dry season.

In the case of Australia, for example, the imposition of an anthropogenic fire regime following Human occupation is considered by some researchers to have resulted in a massive alteration of vegetation from pyrophobic vegetation types such as Casuarina and Araucaria to the pyrophyllic encalypt-dominated ecosystems which cover much of the modern landscape (Singh and Geissler, 1985: Kershatw. 1986). In the words of Pyne (1991)-"With fire, the genus Euculyptus and the genus Homo had a common cause and shared a common future" (p.21).

Several researchers have suggested that humans have been able to substantially modify their enviromment through the use of fire since pre-historic times (e.g. Emiliani et al., 1991; Miller and Magee, 1992: Bird, 1995). Such a view is not universally shared (c.g. Horton, 1982), and the impact of prehistoric anthropogenic burning on the landscape remains a contentious issue, largely because of a paucity of information on the nature of fire regimes before human occupation.

While the study of fire in the modern environment falls mainly within the ambit of ecology and atmospheric chemistry, the earth sciences has an important role to play in providing and interpreting long term fire histories both to determine the effect of large scale (glacial-interglacial) climate changes on fire regimes, and to provide a baseline against which to compare modern fire regimes. The earth sciences can also provide a measure of the importance as a global carbon sink of the carbonaceous products of biomass burning, and their role in the global carbon cycle. In both these cases, robust methodologies are required to be able to quantify the abundance of carbonaceous particulates produced by combustion, and the remainder of this paper attempts to oulline the current status of research in this area.

\section{'Elemental carbon' in the geologic record}

Biomass burning produces a range of carbonized particulate materials known by a variety of terms including charcoal, soot, black carbon, fusain, microcrystalline graphite or elemental carbon. There is a comparably wide range of definitions for this material based on crystallography or chemical composition, or on its susceptibility to either thermal or chemical oxidation. In the discussion below, the term elemental carbon (EC) will be used as a general name encompassing all forms of carbon produced by combustion/pyrolysis.

While the first attempts to measure elemental carbon abundance in sediments were made in the 1970s (Smith et al.. 1973), more recent recognition of the importance of being able to accurately measure EC abundance in a range of sample types has led to an upsurge of researchers working in the field. This interest has also led to a proliferation of techniques for measuring EC in soils, sediments and 
aerosols. While this is a positive development, there are two major problems which will need resolution before reliable and unified progress cin be made by the field as a whole:

\section{Definition and measurement of EC}

As noted above, $E C$ is a continuum of compounds with a wide range of compositions that rarely approach the ideal of pure carbon with a graphitic structure. This means that most studies define EC according to the technique used in the study, and unfortunately there has been virtually no effort as yet, to compare results obtained using techniques or to formulate a standard set of techniques to ensure that results produced by different researchers can be reliably compared with each other.

A survey of the available techniques is presented in Table 1 . In general, the techniques can be categorized into thermal oxidation, chemical oxidation or particle counting. A detailed analysis of the benefits and limitations of all techniques is beyond the scope of this paper, but it worth making some general statements:

The particle counting techniques have the advantage of being able to 'see what you are dealing with', but do not measure the total EC content, only particles greater than a nominal size. It is not easy to discriminate between particles carbonized to varying degrees, and it is also not possible to assess the possibility that particles may decompose or disaggregate over time to particles which are too small to be counted.

The oxidation techniques have the advantage of being able to measure EC of all particle sizes, but as is the case with the particle counting methodologies, do not measure total EC as some $\mathrm{EC}$ will inevitably be oxidized during the treatments. This is because the oxidation techniques operate on the basis that organic carbon will oxidize at a much faster rate than EC, such that only EC is left after a nominated duration of oxidation. As an example of the discrepancies which can arise using different oxidation techniques. Verardo and Ruddiman (1996) concluded that up to $90 \%$ of carbon in marine sediments in the equatorial Atlantic off Africa were $\mathrm{EC}$, while Bird and Cali (in review) found an order of magnitude less $\mathrm{EC}$ was present in sediments a similar distance off the coast of Africa in the equatorial Atlantic on the Sierra Leone Rise. Both studies measured EC according to their definitions, but obviously were not measuring the same component of EC. Resolution of this discrepancy is important because one of the implication of the high EC contents reported by Verardo and Ruddiman (1996) is that EC burial in marine sediments is a major carbon sink. Further implications also flow on into all studies which attempt to estimate palaeoproductivity based on the

Table I Summary of techniques used for the determination of elemental carbon

\begin{tabular}{lll}
\hline study & pretreatment $\quad$ oxidation ${ }^{13}$ material \\
\hline
\end{tabular}

\section{chemical techniques}

Skjemstad et al. (1993.1996)

Emiliani et al., (1991)

sonication/sieving

CD/SD

Rose (1990), Odegaard (1993)

$\mathrm{CD} / \mathrm{SD}$

Smith et al. (1973), Snith (1975)

$\mathrm{CD} / \mathrm{SD}$

Herring (1985)

$\mathrm{CD} / \mathrm{SD}$

Winkler (1994)

CD

Verardo (1997)

$\mathrm{CD}$

Wolbach and Anders (1989)

$\mathrm{CD} / \mathrm{SD}$

Reullan (1996)

$\mathrm{CD} / \mathrm{SD}$

$\mathrm{CD} / \mathrm{SD}$

Bo Lim and Cachier (1996)

$\mathrm{CD} / \mathrm{SD}$

\section{'counting' techniques}

Clark (1988). Clark \& Hussey (1996) thin section prep

Kershaw $(1985,1986)$

$\mathrm{CD} / \mathrm{SD}$

solvent extraction
filtration, $\mathrm{CD}$
filtration
determine biomass

thermal, $340^{\circ} \mathrm{C}, 2 \mathrm{hrs}$

thermal, $340^{\prime \prime} \mathrm{C}, 2 \mathrm{hrs}$

stepped thermal $100-700^{\circ} \mathrm{C}$

burn biomass

$\begin{array}{lll}\text { NMR, coulometry } & \text { no } & \text { So } \\ \text { combustion / MS } & \text { yes } & \text { Se } \\ \text { particle counting } & \text { no } & \text { Se } \\ \text { pulverising /IR spectr. } & \text { no } & \text { Se } \\ \text { pulverising /IR spectr. } & \text { no } & \text { Se } \\ \text { stepped combustion / MS } & \text { yes } & \text { Se } \\ \text { gas chromatography } & \text { no } & \text { Se } \\ \text { weight loss/titration } & \text { yes } & \text { Se } \\ \text { coulometry } & \text { no } & \text { So } \\ \text { coulonetry } & \text { no } & \text { Se } \\ \text { combustion / MS } & \text { yes } & \text { Se.So,Pl }\end{array}$

particle area in thin section no

Se

counting grain mounts no Se

GC/mass-balance

$\mathrm{Pl}, \mathrm{Ae}$

coulometry yes

Pl, Ae

manometry/transmissivity no

$\mathrm{Ac}$

weigh before/after

no

So,Pl

\section{'proxy' techniques}

Venkatesan and Dahl (1989)

Killops and Massoud (1992) solvent extraction nil

solvent extraction nil
GC-MS of PAH's

GC-MS of PAH's no)

no
Se

Se

note: $\mathrm{CD}=$ carbonate dissolution; $\mathrm{SD}=$ silicate dissolution; $\mathrm{MS}=$ mass spectrometry; $\mathrm{GC}=$ gas chromatogrphy; $\mathrm{PAH}=$ polycyclic aromatic hydrocarbon; NMR = nuclear magnetic resonance; $I R=$ infra-red; $R . T .=$ room temperature; So $=$ soil; Se $=$ sediment; $P l=p l a n t:$ Ae $=$ aerosol 
assumption that most of organic carbon in marine sediments is of marine origin.

Even if only those techniques based on acid-dichromate oxidation listed in table 1 are considered, it can be seen that while the same reagent is used in all the studies, the reaction times and temperatures are not consistent between studies, making it impossible to directly compare the results. Bird and Grocke (in press) further found that a series of EC standards produced from different plant materials and treated under identical conditions in acid-dichromate solution, oxidized at very different rates depending on the density and surface area of the original EC particles.

When dealing with changes in EC abundance in the sedimentary record, all techniques suffer from the fact that the transport of EC to the eventual site of accumulation is a complicated process affected by factors such the efficiency of EC production at the site of burning. particle size effects on transport and variations in the intensity and direction of the transporting winds (e.g. Clark and Hussey, 1996).

\section{Stability of EC in the environment}

For measurements of $\mathrm{EC}$ abundance in the geologic record to have any meaning, the material must not be susceptible to significant degradation following burial. In the earth sciences it is generally considered that EC is inert, and that after it is produced it may be physically transported, but does not undergo significant chemical transformation. This contrasts strongly with the view held by archaeologists that at least in tropical environments charcoal does decompose on geological time scales (e.g. Yellen, 1986).

Given that EC is actually a continuum of combustion products, the assumption that EC is truly inert cannot be strictly correct, and it has not been adequately demonstrated that any component EC is truly inert. In reducing conditions such as characterize most marine sediments, EC may be relatively stable (Herring, 1986), possibly because reactive components are metabolized prior to burial, however this same stability may not be the case in oxidizing conditions such as pertaining in soil profiles and some terrestrial sedimentary sequences.

A recent study of a savanna plot in Zimbabwe that has been protected from fire for the last 50 years Bird (unpubl data) found that a significant proportion of $\mathrm{EC}$ is no longer present in the surface soil, compared with surrounding burnt savanna sites. There is also carbon-isotope evidence that large charcoal particles are gradually broken down into smaller particles and ultimately either being illuviated into deeper parts of the soil profile, oxidized by photochemical or biological means, or possibly translocated into the humic acid fraction of the soil carbon pool (Haumaier and Zech, 1995).

The conclusion that $\mathrm{EC}$ is not stable in oxidizing environments is supported by qualitative evidence from Australia which suggests that charcoal is commonly absent or sparse in the deeper levels of many archaeological sites, even though the sites were occupied during the deposition of the EC-poor leveis, and higher in the same deposits $\mathbf{E C}$ is abundant (R. Jones pers. commun.).

The above statements must be considered speculative at this stage, but do reflect the very poor state of knowledge concerning the fate of EC in the environment and the pathways by which EC may in fact continue to be actively rather than passively involved in the carbon cycle after its formation. An example of where this knowledge becomes important is in the determination of $\mathrm{EC}$ abundances in soils. Skjemstad. (1986) has suggested that a significant component of many soils is EC (up to $30 \%$ ), and that if EC in soil profiles is not taken into account, then the amount of 'active' carbon in the soil maybe considerably over-estimated. This conclusion is predicated on the presumption that the EC is actually inert, and while on shorter time-scales this may be reasonable, it has yet to be demonstrated that this is true on decadal time-scales.

\section{Conclusions}

The growth of interest in EC in recent years testities to its importance in a variety of spheres of environmental research of relevance to the earth sciences, but like any emerging field, research efforts are currently disjointed and disparate. The current problems of definition and consistency in measurement can be addressed by inter-comparison of techniques using standard samples, with a view to subsequent standardization on one or more agreed analytical protocols. The addition of $\mathrm{H} / \mathrm{C}$ and $\mathrm{C} / \mathrm{N}$ ratio measurements as well as carbonisotope measurements $\left({ }^{1.3} \mathrm{C}\right.$ and $\left.{ }^{14} \mathrm{C}\right)$, can potentially facilitale a much greater understanding of what is actually being determined ats EC by different techniques, as well as the source of that material. The concern as to the degree to which EC is 'inert' can be addressed by carefully designed field and laboratory studies.

\section{References}

Balter, M., 1995. Did Homo erectus tame tire first?: Science, v. 268, pp. 1570.

Bird, M.I.. 1995, Fire, prehistoric humanity and the environment: Interdisciplinary Science Reviews, v. 20, pp. 141-154.

Bird, M.I., and Cali. J.A., A million-year fire history for the African Sahel from ODP-668B, Sierra Leone Rise: Abstr. Conf. Desert margin change in Africa since 135,000 BP: Implications for water, carbon and man. Nouakchott, Mauritania, 5-8 January, pp. 6.

Cachier, H., Bremond. M.P., and Buat-Menard, P., 1989a. Determination of atmospheric soot carbon with a simple thermal method: Tellus. v. $41 \mathrm{~B}$. pp. $379-390$

Cachier, H., Bremond, M.P., and Buat-Menard, P., 1989b. Carbonaceous aerosols from different tropical biomass burning sources: Nature, v. 340 . pp. $37 \mid-373$.

Chylck, P., Johnson, B., and Damiano. P.A., 1995. Biomass burning and black carbon in the GISP2 ice core: Geophysical Research Letters, v. 22? pp. 89-92.

Chylek, P. Srivastava, V., Cahenzli, L., Pinnick. R.G., Dod, R.L., Novakov. T., Cook, T.L., and Hinds, B.D., 1987, Aerosol and graphitic carbon content of snow: Journat of Geophysical Research, v. 92, pp. $9801-9809$.

Clark, J.S., 1988. Stratigraphic charcoal analysis on petrographic thin sections: Application to fire history in northwestern Minnesota: Quaternary Research, v. 30, pp. 81-91.

Clark, J.S., and Hussey, T.C., 1996, Estimating the mass flux of charcoal from sedimentary records: effects of particle size, morphology and orientation: The Holocene, v. 6, pp. 129-144.

Emiliani. C., Price. D.A., and Seipp, J., 1991. Is the post-glacial artificial?, in Taylor, H.P, O'Neil, J.R., and Kaplan, I.R., eds, Stable-isotope geochemistry: A tribute to Samuel Epstein: The Geochemical Society Special Publication, no..3, pp. 229-231.

Fearnside, P.M., Leal, L., and Fernandes. F.M.. 1993, Rainforest burning and the global carbon budget: Biomass, combustion efficiency and charcoal formation in the Brazilian Amazon: Journal of Geophysical Research, v. 98, pp. 16733-16743.

Gowlett, J.A.J., Harris, J.W.K., Walton, D., and Wood, B.A., 1981, Early archaeological sites, hominid remains and traces of fire from Chesowanja, Kenya: Nature, v. 294, pp. 125-129.

Haumaier, L., and Zech. W., 1995, Black carbon - possible source of highly aromatic components of soil humic acids: Organic geochemistry. v. 23. pp. $191-196$.

Herring, J.R., 1985, Charcoal flux into sediments of the north Pacific Ocean the Cenozoic record of burning. in The carbon cycle and atmospheric $\mathrm{CO}_{2}$ : Natural variations from Archean to present: Geophysical Monograph, v. 32, pp. $419-441$

Horton, D.R., 1982, The burning question: Aborigines, fire and Australian ecosystems: Mankind, v. 13. pp. 237-251.

Kershaw, A.P., 1985, An extended late Quaternary vegetation record from northeast Queensland and its implications for the seasonal tropies of Australia: Proceedings of the Ecological Society of Ausralia, v. 13, pp. 179-189.

Kershaw, A.P.. 1986. Climatic change and aboriginal burning in northeast Australia during the last two glacial/interglacial cycles: Nature, v. 322, pp. $47-49$. 
Killops, S.D., and Massoud, M.S., 1992, Polycyclic aromatic hydrocarbons of pyrolytic origin in ancient sediments: evidence for Jurassic fires: Organic geochemistry, v. 18, pp. 1-7.

Kuhlbusch, T.A.J., and Crutzen, P.J., 1995, Toward a global estimate of black carbon on residues of vegetation fires representing a sink of atmospheric $\mathrm{CO}_{2}$ and a source of $\mathrm{O}_{2}$ : Global Biogeochemical Cycles, v. 9, pp. 491-501.

Lim, B., and Cachier, H., 1996, Determination of black carbon by chemical oxidation and thermal treatment in recent marine and lake sediments and Cretaceous-Tertiary clays, Chemical Geology, v. 131, pp. 143-154.

Miller, G.H., and Magee, J., 1992, Drought in the Australian outback: Anthropogenic impact on regional climate (abs): American Geophysical Union, Fall Meeting, pp. 104.

Monnier, J-L., et al., 1994, A new regional group of the Lower Palaeolithic in Brittany (France), recently dated by electron spin resonance: Comptes Rendus Academie des Seances, Paris, v. 319 (ser.II), pp. 155-160.

Odegaard, B.V., 1993, The sedimęntary record of spheroidal carbonaceous fly-ash particles in shallow Danish lakes: Journal of Paleolimnology, v. 8, pp. $17 \mathrm{I}-187$.

Pyne, S.J., 1991, Burning Bush: A Fire History of Australia. Holt and Co. N.Y.

Rose, N.L., 1990, A method for the extraction of carbonaceous particles from lake sediment: Journal of Paleolimnology, v. 3, pp. 45-53.

Ruellan, S., 1996, Archivage sedimentaire et glaciare du carbone particulaire. MSc. Thesis: Univ. Paris VII (unpubl.).

Shukla, J., Nobre, C.A., and Sellers, P., 1990, Amazon deforestation and climate change: Science, v. 247, pp. 1322-1325.

Singh, G., and Geissler, E.A., 1985, Late Cainozoic history of fire, lake levels and climate at Lake George N.S.W., Australia: Philosophical Transactions of the Royal Society of London, v. 311, pp. $379-447$.

Skjemstad, J.O., Janik, L.J., Head, M.J., and McClure, S.G., 1993, High energy ultraviolet photo-oxidation: a novel technique for studying physically protected matter in clay- and silt-sized aggregates: Journal of Soil Science, v. 44, pp. 485-499.

Skjemstad, J.O., Clarke, P., Taylor, J.A., Oades, J.M., and McClure, S.G., 1996. The chemistry and nature of protected carbon in soil: Australian Journal of Soil Research, v. 34, pp. 251-277.
Smith D.M., Griffin, J.J., and Goldberg, E.D., 1973, Elemental carbon in marine sediments: a baseline for burning: Nature, v. 241, pp. 268-270.

Smith D.M., Griffin, J.J., and Goldberg, E.D., 1975, Spectrometric method for the quantitative determination of elemental carbon: Analytical Chemistry, v. 47, pp. 233-238.

Venkatesan, M.I., and Dahl, J., 1989, Organic geochemical evidence from global fires at the Cretaceous/Tertiary boundary: Nature, v. 338, pp. 57-60.

Verardo, D.J., 1997, Charcoal analysis in marine sediments: Limnology and Oceanography, v. 42, pp. 192-197.

Verardo, D.J., and Ruddiman, W.F., 1996, Late Pleistocene charcoal in tropical Atlantic deep-sea sediments: Climatic and geochemical significance: Geology, v. 24, pp. 855-857.

Winkler, M.G., 1994, Sensing plant community and climate change by charcoal carbon-isotope analysis: Ecoscience, v. 1, pp. 340-345.

Wolbach, W.S., Gilmour, I., Anders, E., and Orth, C.J., 1988, Global fire at the Cretaceous-Tertiary boundary: Nature, v. 334, pp. 665-669.

Wolbach, W.S., and Anders, E., 1989. Elemental carbon in sediments: Determination and isotopic analysis in the presence of kerogen: Geochimica Cosmochimica Acta, v. 53, pp.1637-1647.

Xue, Y.. 1993, The influence and mechanisms of biosphere feedback on African climate: IAHS Publication, v. 214, pp. 119-124.

Dr. Michael Bird is an isotope geochemist who currently holds a Queen Elizabeth II fellowship in the Research School of Earth Sciences, Australian National University, Australia. His research interests include the role of soils in the global carbon cycle, records of fire incidence for Australia and Africa in the past, and the relationship between anthropogenic burning and ecosystem change.

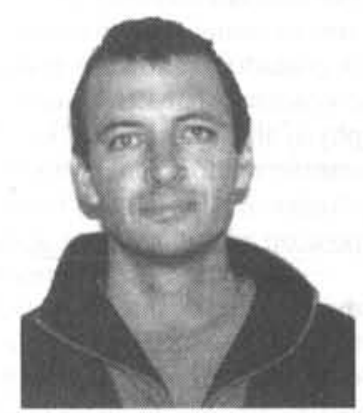

\section{Hutchison 'Young Scientist' Fund}

William Watt Hutchison, "Hutch" to his many friends around the world, was a Scots-born Canadian geologist who served Canada and the IUGS in myriad dynamic and creative ways. Most notably, he served as the IUGS Secretary General (1976-1980) at a pivotal time in its history, and as IUGS President (1984-1987). The same boundless energy, enthusiasm, skill in communications, and ability to foster teamwork that characterized his work with the IUGS also carried him to preeminent scientific administrative positions in the Canadian Government, where he served as Director General of the Geological Survey of Canada and as Assistant Deputy Minister of Earth Sciences. His distinguished career was terminated in 1987 by his untimely death at the age of 52 , following a painful struggle with cancer.

One of Hutch's last wishes was to establish under IUGS auspices a memorial foundation intended to promote the professional growth of deserving, meritorious young scientists from around the world by supporting their participation in important IUGS-sponsored conferences. The first 3 beneficiaries of the Hutchinson "Young Scientist Foundation" attended the 28th International Geological Congress (IGC) in Washington, D.C., in 1989.

Currently, income earned as interest on the Hutchison fund is insufficient to sustain comparable grants every four years without seriously eroding the principal. For that reason, the IUGS made no grants from the fund for the 30th IGC, preferring instead to strengthen the fund by allowing it to earn interest for a longer period of time and by appealing for donations from the international geologic community. It is expected that grants from the fund will again support deserving young scientists to attend the 31st IGC in the year 2000. The Hutchison "Young Scientist Foundation" is a worthy cause that honors a fine, caring man and a distinguished, public-spirited scientist and administrator. The foundation also celebrates and promotes those things that gave Hutch the most professional satisfaction: geology, international scientific collaboration, and stimulating young minds.

The IUGS welcomes contributions to the Hutchison "Young Scientist Foundation." Please send donations to:

Dr. John A. Reinemund
P.O. Box 890
Leesburg, VA 20178 USA
Fax: +1 7037774463
Tel: +1 7037771491

Checks in US dollars or Visa/Mastercard (please include account number and expiration date) are preferred in order to avoid the high cost of currency conversions. Residents of the U.S.A. are reminded that charitable gifts of this nature are tax deductible. 